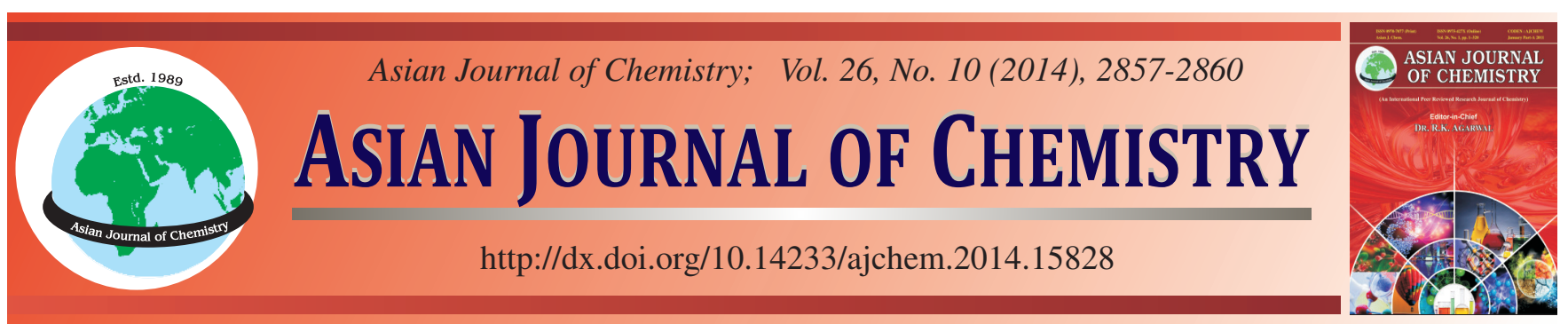

\title{
Extractive Spectrophotometric for Determination of Dihydroergocryptine Mesylate in Pharmaceutical Preparations
}

\author{
Malek OKdeh ${ }^{1, *}$, Amir Alhaj Sakur ${ }^{2}$ and Banana Alfares ${ }^{1}$
}

${ }^{1}$ Department of Chemistry, Faculty of Science, Teshreen University, Lattakia, Syria

${ }^{2}$ Department of Analytical and Food Chemistry, Faculty of Pharmacy, Aleppo University, Aleppo, Syria

*Corresponding author: E-mail: dr.malekokdeh@yahoo.com

\begin{abstract}
Simple, accurate and highly sensitive spectrophotometric method has been developed for the rapid determination of dihydroergocryptine mesylate in pure form and pharmaceutical formulations. The spectrophotometric method was based on the formation of binary complex (ion-pair complex) between the dihydroergocryptine mesylate and chromotrope $2 \mathrm{R}$ in acidic buffer, giving purple color. The absorbance of dichloromethane extracted complex was measured at $531 \mathrm{~nm}$. The effects of analytical parameters on the reported systems were investigated. The complexation reaction was extremely rapid at room temperature and the absorption value remains unchanged up to $24 \mathrm{~h}$. Beer's law was obeyed in the concentration ranges of 3-180 $\mu \mathrm{g} / \mathrm{mL}$, detection limit was $0.08 \mu \mathrm{g} / \mathrm{mL}$ and the molar absorptivity coefficient were $6.8 \times 10^{3} \mathrm{~L} \mathrm{~mol}^{-1} \mathrm{~cm}^{-1}$ for chromotrope $2 \mathrm{R}$. Recoveries were between $97.20-101.11 \%$. Interferences of the other ingredients and excipients were not observed.
\end{abstract}

Keywords: Extractive spectrophotometry, Complex formation, Dihydroergocryptine mesylate, Chromotrope 2R.

ᄂ - - - - - - - - - - - - - - - - - - - - - - - - - - - -

\section{INTRODUCTION}

Dihydroergocryptine mesylate, $(2 \mathrm{R}, 4 \mathrm{R}, 7 \mathrm{R})-N-[(1 \mathrm{~S}, 2 \mathrm{~S}$, 4R,7S)-2-hydroxy-7-(2-methylpropyl)-5,8-dioxo- 4-(propan2-yl)-3-oxa-6,9-diazatricyclo[7.3.0.02,6]dodecan-4-yl]-6methyl-6,11-diazatetracyclo[7.6.1.02,7.012,16]hexadeca-1 (16),9,12,14-tetraene-4-carboxamide, molecular weight 673.8 $\mathrm{g} \mathrm{mol}^{-1}$ (Fig. 1). It belongs to the pharmaco-therapeutic group peripheral vasodilator ( $\mathrm{C}$ : caddiovascular system), there is dihydroergocryptine mesylate with caffeine and this drug indicated in age related minor neurological disorders in reynaud, syndrome (circulatory disorders of the extremities) ${ }^{1}$.

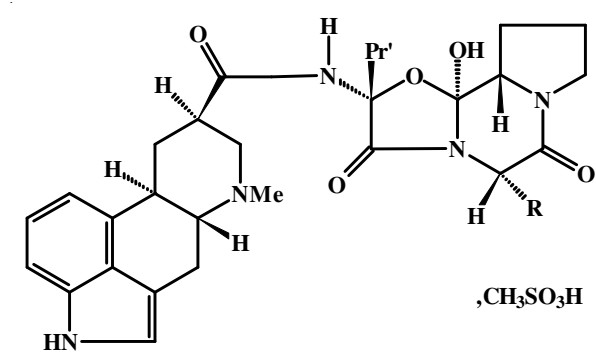

Fig. 1. Chemical structure of dihydroergocryptine mesylate

Few methods have been described for the determination of dihydroergocryptine mesylate, in human plasma and urine samples using on-line sample extraction-column-switching reversed-phase liquid chromatography-mass spectrometry ${ }^{2}$, separation and determination of four ergot alkaloids, dihydroergotameme-, dihydroergocornine-, dihydroergocryptine- and dihydroergocristine methanesulfonates by high performance liquid chromatography ${ }^{3}$. The United State Pharmacopoeia and British Pharmacopoeia do not indicate an official method for the quantification of dihydroergocryptine mesylate and no extractive spectrophotometric methods for the determination of dihydroergocryptine mesylate have been reported in pharmaceutical preparation yet.

Many materials have been determined by using chromotrope $2 \mathrm{R}$ e.g., spectrophotometric determination meclozine $\mathrm{HCl}$ and papaverine $\mathrm{HCl}$ in their pharmaceutical formulations ${ }^{4}$, sildenafil citrate in pure form and in pharmaceutical formulation $^{5}$ and many extractive spectrophotometric methods for the determination active material in pharmaceutical preparations for example doxepin hydrochloride ${ }^{6}$, nifedipine $^{7}$, phenothiazine derivatives ${ }^{8}$, fluoxetine and fluvoxamine ${ }^{9}$, fluoroquinolone derivatives ${ }^{10}$, ceterizine $\mathrm{HCl}^{11}$, sildenafil citrate $(\text { Viagra })^{12}$, sulphonamide drugs in pure and pharmaceutical preparations through ion-pair ${ }^{13}$, anti-Parkinsonian drug ${ }^{14}$, cyclizine $^{15}$, disopyramide and irbesartan ${ }^{16}$, trifluoperazine hydrochloride ${ }^{17}$ and levofloxacin ${ }^{18}$.

In the present work, new simple and sensitive analytical method was developed for the determination of dihydro- 
ergocryptine mesylate. The method was applied for the analysis of international and local pharmaceutical products samples.

\section{EXPERIMENTAL}

Measurements were made on a Jasco V-650 model spectrophotometer UV-Visible (Japan Spectroscopic Co. Ltd., Tokyo) with a scanning speed of $400 \mathrm{~nm} / \mathrm{min}$ and a bandwidth of $2 \mathrm{~nm}$, equipped with $10 \mathrm{~mm}$ matched quartz cells. All absorption spectra were made for electronic spectral measurements between (190-1100 nm). The $\mathrm{pH}$ measurements were made with CRISON pH meter Model GLP21 made in EU.

Stock standard solution of dihydroergocryptine mesylate $\left(1 \times 10^{-3} \mathrm{M}\right)$ was prepared by dissolving $67.8 \mathrm{mg}$ (considering the purity) of drug in double distilled water and diluted to the mark in $100 \mathrm{~mL}$ volumetric flask. The standard solution was prepared by dilution of the stock standard solution with double distilled water to reach concentration $\left(1 \times 10^{-4} \mathrm{M}\right)$ of dihydroergocryptine mesylate. This solution was stored in well-closed vessel, the solution is stable. Solutions of reagent Chromotrope $2 \mathrm{R}$ were prepared with a concentration of $\left(1 \times 10^{-3} \mathrm{M}\right)$ by dissolving suitable weight of the reagent in double distilled water and diluted to the mark in $100 \mathrm{~mL}$ volumetric flasks separately.

The aqueous solution of chromotrope $2 \mathrm{R}$ dye was stable for several months. Spectroscopic grade dichloromethane was used for extraction from SCP (Surchem product Ltd, England).

Procedure for the assay of bulk sample: Aliquots of the standard dihydroergocryptine mesylate solutions were transferred into a series of $50 \mathrm{~mL}$ separating funnels, $3 \mathrm{~mL}$ of Briton buffer and $3.5 \mathrm{~mL}$ of reagent chromotrope $2 \mathrm{R}$ were added and mixed well, a $10 \mathrm{~mL}$ amount of dichloromethane was added with three portions and the mixture was shaken well. The formed ion associates were extracted with $3 \mathrm{~mL}$ by shaking for $5 \mathrm{~min}$, then repeating the extraction step twice by using new $3 \mathrm{~mL}$ aliquots of the extractant for every extraction. The reaction mixture was allowed to separate into two phases. The organic layer was collected into $10 \mathrm{~mL}$ calibrated measuring flask and the volume was made up to the mark with the extractant solvent. The absorbance of the separated dichloromethane layer was measured at a maximum $531 \mathrm{~nm}$, for the complex chromotrope 2R-dihydroergocryptine mesylate, against the reagent blank. The standard calibration plot was prepared to calculate the amount of the analyzed drug in bulk samples. All measurements were carried out at room temperature $\left(25 \pm 2{ }^{\circ} \mathrm{C}\right)$.

Procedure for formulations: The contents of 20 tablets of dihydroergocryptine mesylate drugs were weighed, powdered and an accurately weighed portion equivalent to $4 \mathrm{mg}$ of the drug was dissolved in double distilled water, shaken in mechanical shaker for $5 \mathrm{~min}$ and then filtered. The filtrate was made up to $100 \mathrm{ml}$ volumetric flask. The suitable aliquot was analyzed using the procedure described earlier.

\section{RESULTS AND DISCUSSION}

Preliminary investigations have been shown that dihydroergocryptine mesylate reacts with chromotrope $2 \mathrm{R}$ in Britton buffer to give dichloromethane-soluble ion-association complexes. The optimum reaction conditions for quantitative determination of the ion pair complex was established via a number of preliminary experiments.

Several parameters such as acidity, type and amount of acid added, reagent concentration, sequence of addition and effect of extracting solvent were optimized to achieve high sensitivity, low blank reading and reproducible results.

Effect of extracting solvent: Several organic solvents (ethyl ether, chloroform, dichloromethane, ethyl acetate, carbon tetra chloride) were examined for their ability to extract dihydroergocryptine mesylate-dye ion-pair complexes. The dichloromethane was found to be the most suitable solvent for quantitative extraction of the complex.

Effect of time and temperature: The effect of time on the formation and stability of the ion-associates was studied by measuring the absorbencies of the extracted ion-associates at increasing time intervals, the results show that the ion-associates were formed almost instantaneously in the cases at room temperature $\left(25 \pm 2{ }^{\circ} \mathrm{C}\right)$. The color of the dihydroergocryptine mesylate-chromotrope $2 \mathrm{R}$ remained stable for 8-10 h. after these intervals, a slight decrease in color intensity occurred.

Effect of acidity: The effect of $\mathrm{pH}$ was studied by extracting the colored complex in the presence of various buffers such as Briton, acetate, borate and acid media. It was observed that the maximum color intensity and constant absorbance were found in Briton buffer of $\mathrm{pH} 1.8$ for dihydroergocryptine mesylate-chromotrope $2 \mathrm{R}$ system using $3 \mathrm{~mL}$ of buffer as shown in Fig. 2.

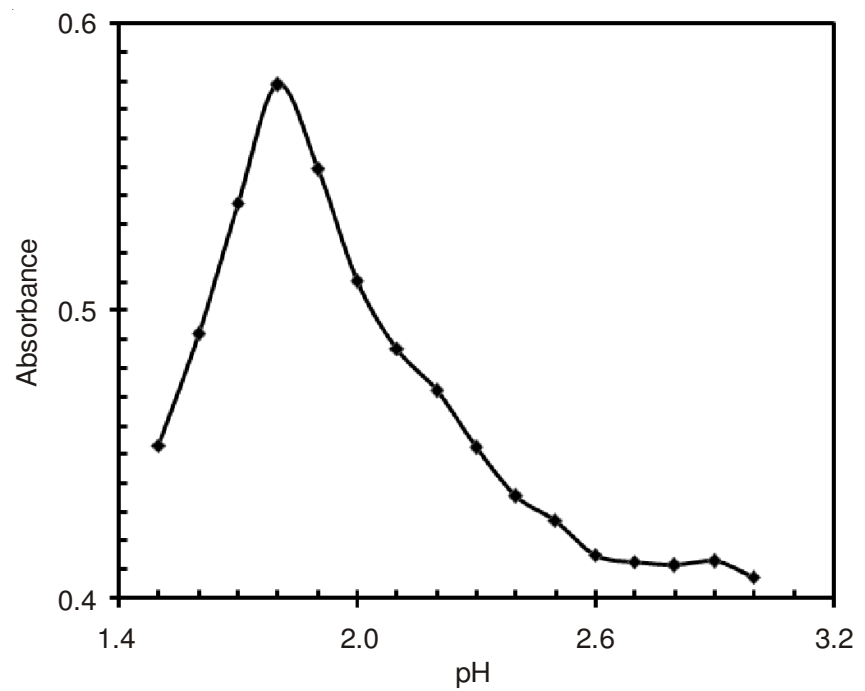

Fig. 2. Effect of the pH value on absorption of dihydroergocryptine mesylate-dye complex

Effect of amount of Britton buffer: The optimum amount of Britton buffer for the assay of drugs was studied. $3 \mathrm{~mL}$ of Britton buffer $\mathrm{pH} 1.8$ was sufficient for complete color development for dihydroergocryptine mesylate-dye complex (Fig. 3).

Molar ratio determination of dihydroergocryptine mesylate-dye complexes: The molar ratio of the drug to dye of the colored complex was determined using the molar ratio ${ }^{19}$ and continuous variation ${ }^{20}$ methods. The ratio were found to be $1: 2$ for dihydroergocryptine mesylate:chromotrope $2 \mathrm{R}$ (Figs. 4 and 5). 


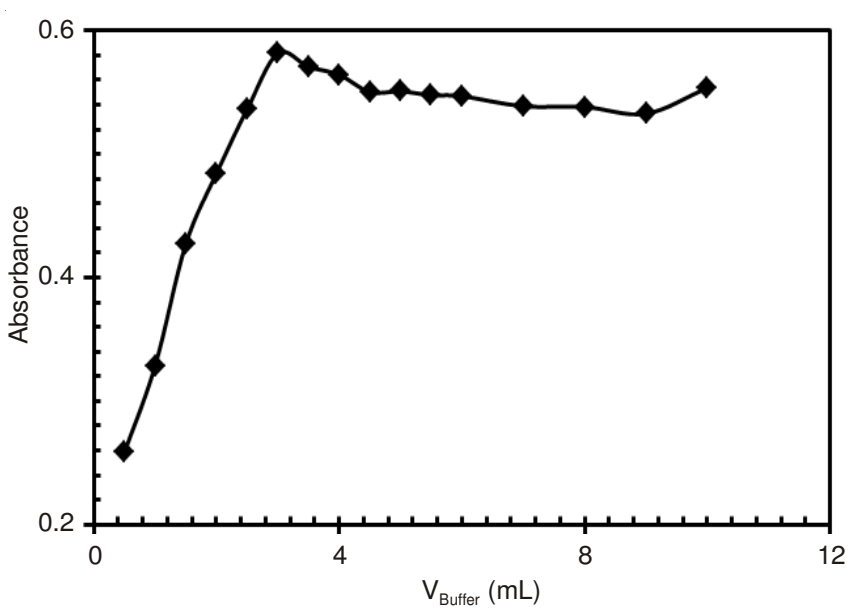

Fig. 3. Effect of the buffer volume $(\mathrm{pH}=1.8)$ on absorption of dihydroergocryptine mesylate-dye complex

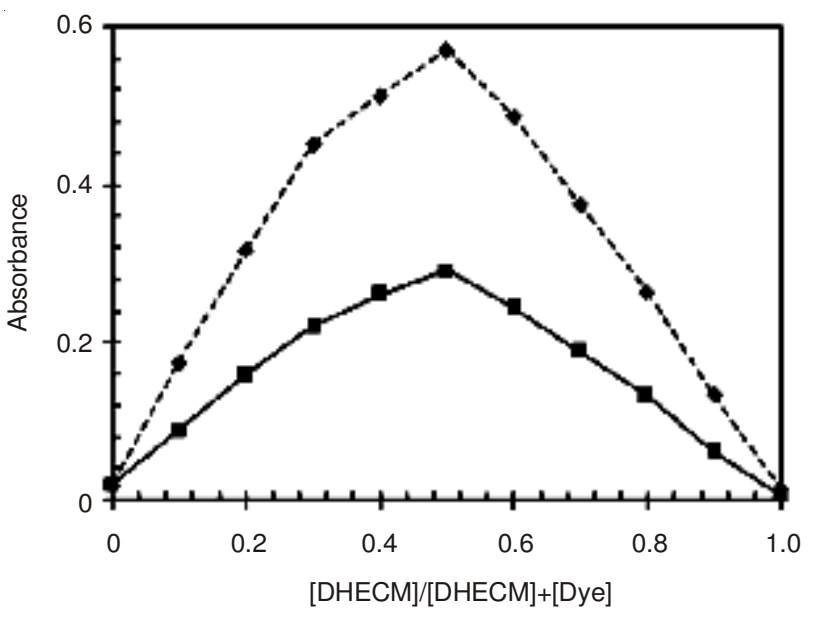

Fig. 4. Continuous Variations plots for dihydroergocryptine mesylate-dye

Linearity and range: Beer's law limits, molar absorptivity, linear regression equation, correlation coefficient and detection limit determined for method is given in Table-1. A linear relationship was found between the absorbance at $\lambda_{\max }$ and the concentration of the drug in the ranges $3-180 \mu \mathrm{g} / \mathrm{mL}$ for chromotrope $2 \mathrm{R}$.

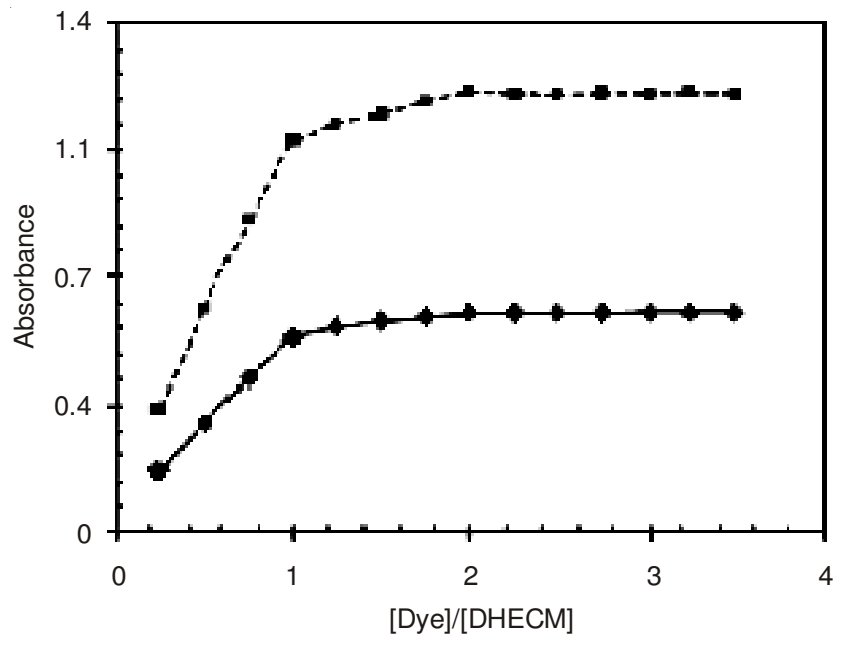

Fig. 5. Molar ratio plots for dihydroergocryptine mesylate-dye

\begin{tabular}{lc}
\multicolumn{2}{c}{ TABLE-1 } \\
\multicolumn{1}{c}{ SPECTRAL CHARACTERISTICS OF DIHYDROE } \\
GOCRYPTINE MESYLATE-DYE COMPLEXES
\end{tabular}

The graph shows negligible intercept and is described by the regression equation, $\mathrm{A}=\mathrm{mC}+\mathrm{b}$ (where $\mathrm{A}$ is the absorbance of $1 \mathrm{~cm}$ layer, $\mathrm{m}$ is the slope, $\mathrm{b}$ is the intercept and $\mathrm{C}$ is the concentration of the measured solution in $\mu \mathrm{g} \mathrm{mL}^{-1}$ ) obtained by the least-squares method ${ }^{21}$. The high molar absorptivity of the resulting colored complexe indicate the good sensitivity of the method (Fig. 6).

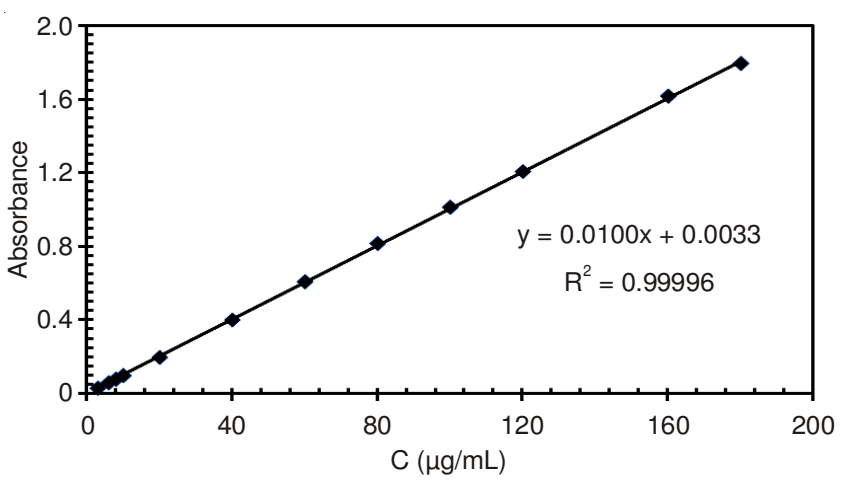

Fig. 6. Calibration plot of dihydroergocryptine mesylate using chromotrope 2R

Accuracy and precision: The results obtained are summarized in Table-2. The low values of relative standard deviation (RSD) indicate good precision and reproducibility of the method. The average percent recoveries obtained were $97.20-$ $101.11 \%$ for chromotrope $2 \mathrm{R}$, indicating good accuracy of the methods.

Application to pharmaceutical dosage forms: The proposed method have been successfully applied to the determination of dihydroergocryptine mesylate in pharmaceutical preparations Table-3. The ingredients in the tablets did not interfere in the experiments.

\section{Conclusion}

The proposed method for the estimation of dihydroergocryptine mesylate using chromotrope $2 \mathrm{R}$ is better than many reported methods. The method is rapid, simple and have good sensitivity and accuracy. Proposed method makes use of simple reagent, which an ordinary analytical laboratory can afford. The high recovery percentage and low relative standard deviation reflect the high accuracy and precision of the proposed method. The method is easy, applicable to a wide 


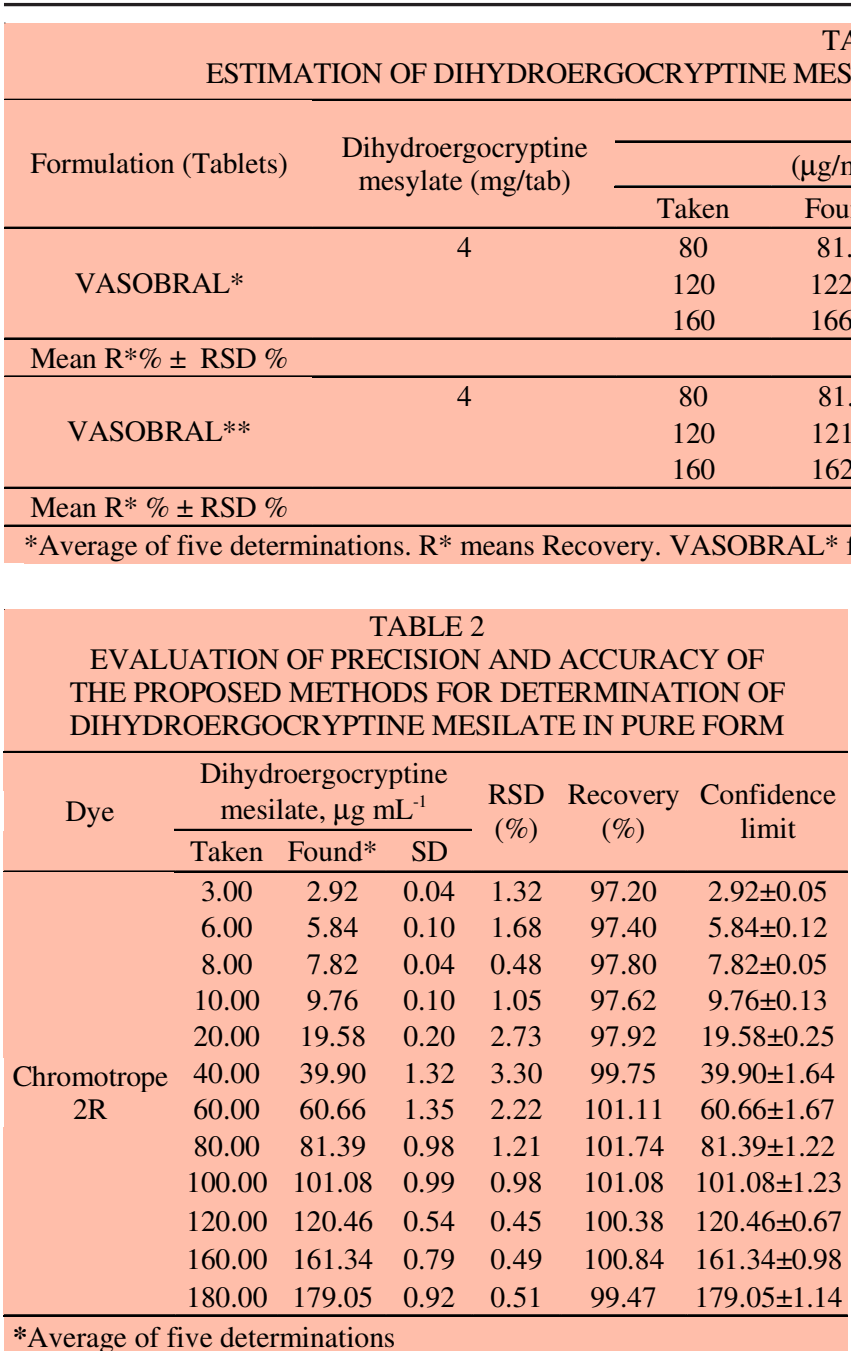

range of concentration, besides being less time consuming and depend on simple reagent which is available, thus offering economic and acceptable methods for the routine determination of dihydroergocryptine mesylate in its formulations.

\section{REFERENCES}

1. L. Battistin, P.G. Bardin, F. Ferro-Milone, C. Ravenna, V. Toso and G. Reboldi, Acta Neurol. Scand., 99, 36 (1999).
TABLE-3

SYLATE IN (DHECM) TABLETS AND ORAL SOLUTION Chromotrope $2 \mathrm{R}$

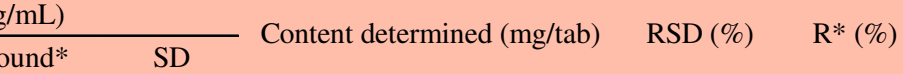

$\begin{array}{lllll}81.70 & 1.14 & 4.09 & 1.40 & 102.12\end{array}$

$22.60 \quad 0.72$

4.09

$0.59 \quad 102.17$

0.91

$4.16-0.55 \quad 103.91$

$102.73 \pm 1.15$

$81.09 \quad 0.37$

0.73

0.51

4.05

0.46

$62.43 \quad 0.51$

$101.47 \pm 0.66$

4.06

4.06

$0.46 \quad 101.37$

0.60

101.53

$0.31 \quad 101.52$

K.C Pharma (Syria). VASOBRAL** from Chiesi (Italy)

2. G. Friedrich, K. Appel, T. Rose, M. Wangemann, M. Althaus and K. Rissler, J. Chromatogr. B Analyt. Technol. Biomed. Life Sci., 808, 131 (2004).

3. S.L. Ali and T. Strittmatter, J. Pharmaceut., 4, 111 (1979).

4. N.T. Abdel-Ghani and A.F. Shoukry and Y.M. Issa and O.A. Wahdan, J. Pharm. Biomed. Anal., 28, 373 (2002).

5. Y.M. Issa, W.F. El-Hawary, A.F.A. Youssef and A.R. Senosy, Spectrochim. Acta A, 75, 1297 (2010).

6. W. Misiuk, IL Farmaco, 60, 61 (2005).

7. A. Moretto, L. Tesolin, F. Marsilio, M. Schiavon, M. Berna and F.M. Veronese, IL Farmaco, 59, 1 (2004).

8. K. Basavaiah and G. Krishnamurthy, Talanta, 46, 665 (1998).

9. B. Starczewska and K. Mielech, J. Pharm. Biomed. Anal., 23, 243 (2000).

10. C.S.P. Sastry, K.R. Rao and D.S. Prasad, Talanta, 42, 3 (1995).

11. B.G. Gowda, M.B. Melwanki and J. Seetharamappa, J. Pharm. Biomed. Anal., 25, 1021 (2001).

12. N.D. Dinesh, P. Nagaraja, N.M.M. Gowda and K.S. Rangappa, Talanta, 57, 757 (2002).

13. F. El-Baz, J. Adv. Res, 1, 3 (2010).

14. M. Iqbal, Z. Khatri, A. Ahmed, J. Mughal and K. Ahmed, J. Saud. Chem. Soc., 16, 1 (2012).

15. A.-S.H. Nora, Saudi Pharm. J., 20, 3 (2012).

16. H.E. Abdellatef, Spectrochim. Acta A, 66, 1248 (2007).

17. M.E.M. Hassouna, A.M. Adawi and E.A. Al, Egypt. J. Forensic Sci., 2, 62 (2012).

18. S. Ashour and R. Al-Khalil, IL Farmaco, 60, 771 (2005).

19. J.H. Yoe and A.L. Jones, Ind. Eng. Chem. (Anal. Ed.), 16, 111 (1944).

20. C.W. Vosburgh and R.G. Cooper, J. Am. Chem. Soc., 63, 437 (1941).

21. J.C. Miller and J.N. Miller, Statistics for Analytical Chemistry, Ellis Horwood, Chichester, edn. 3, pp. 119-130 (1993). 